\title{
New Posterior Auricular Perichondrial Cutaneous Graft for Stable Reconstruction of Nasal Defects
}

\author{
Daniel Felix Kalbermatten M.D., Martin Haug M.D., Reto Wettstein M.D., \\ Dirk Johannes Schaefer M.D., and Gerhard Pierer M.D. \\ Basel, Switzerland
}

\begin{abstract}
The perichondrial cutaneous graft (PCCG), a reliable composite graft that provides stability, is routinely harvested from the anterior conchal bowl. This established PCCG was simplified by using the less conspicuous posterior auricular donor site, which can be closed without the need of cartilage resection for reconstruction with a postauricular interpolated skin island. Patients with basal cell carcinoma of the nose underwent reconstruction of the nose with a PCCG if parts of the tip cartilage or the fibrofatty tissue were resected. The defect surface area was assessed with a template. Follow-up evaluation included assessment of graft survival, donor-site morbidity, nostril stability, and aesthetic outcome. Of the 14 patients included in the study, whose average defect sizes were $2 \mathrm{~cm}^{2}$ (ala) and $2.5 \mathrm{~cm}^{2}$ (tip), 79\% showed primary complete healing. Nostril stability was symmetrical 6 months postoperatively, and no contractions or depressed contour had occurred. In one case, a hyperpigmented area resulted in a slightly imperfect color match. All the donor sites healed without deformity or destabilization of the ear. With the use of this new posterior auricular donor site for graft harvest, functional, stable, and aesthetic reconstruction of the nose can be achieved. The graft- and donor-site morbidity rates are very low, and the results are fully satisfying.
\end{abstract}

Key words: Ear cartilage-PCCG-Perichondrial cutaneous graft_-Posterior auricular donor site - Rhinoplasty

Correspondence to D. F. Kalbermatten M.D., F.M.H., E.B.O.P.R.A.S., Department of Plastic, Reconstructive, and Aesthetic Surgery, University of Basel, 4031 Basel, Switzerland; email: daniel.kalbermatten@bluewin.ch
The perichondrial cutaneous graft (PCCG) was introduced in 1977 by Brent and Ott [1]. The PCCG is a reliable and versatile composite graft with unique properties for reconstructive surgery [9]. This graft consists of an anterior conchal skin layer including subcutaneous tissue and a fine perichondrial layer. It can be a valuable means for reconstruction of facial defects. Clinical applications of the PCCG include reconstruction of auricular defects, ectropion correction, and coverage of facial and nasal defects. The PCCG is routinely harvested from the anterior conchal bowl, and the donor defect is closed after cartilage resection with a postauricular interpolated skin island flap [1,5-8].

The operative procedure, performed with the patient under local anaesthesia, involves a quick harvest of the anterior conchal bowl skin including the subcutaneous tissue and the ear cartilage. After the harvest, the cartilage is removed from the graft, leaving the perichondrial layer intact. The resulting PCCG consisting of anterior conchal skin, subcutaneous skin, and a fine perichondral layer can be sutured into the defect. The conchal donor site, including the removed conchal cartilage, must be reconstructed with a postauricular interpolated skin island.

In our study, we simplified the established PCCG by using a posterior auricular donor site instead of the anterior conchal bowl (Fig. 1). One concern raised is that the posterior location of the PCCG would not be suitable for grafting because of the looser connection between the skin and the perichondrial layer, as compared with the anterior donor site, which consists of thin skin, scant subcutaneous tissue, and tight connections to the perichondrium. 


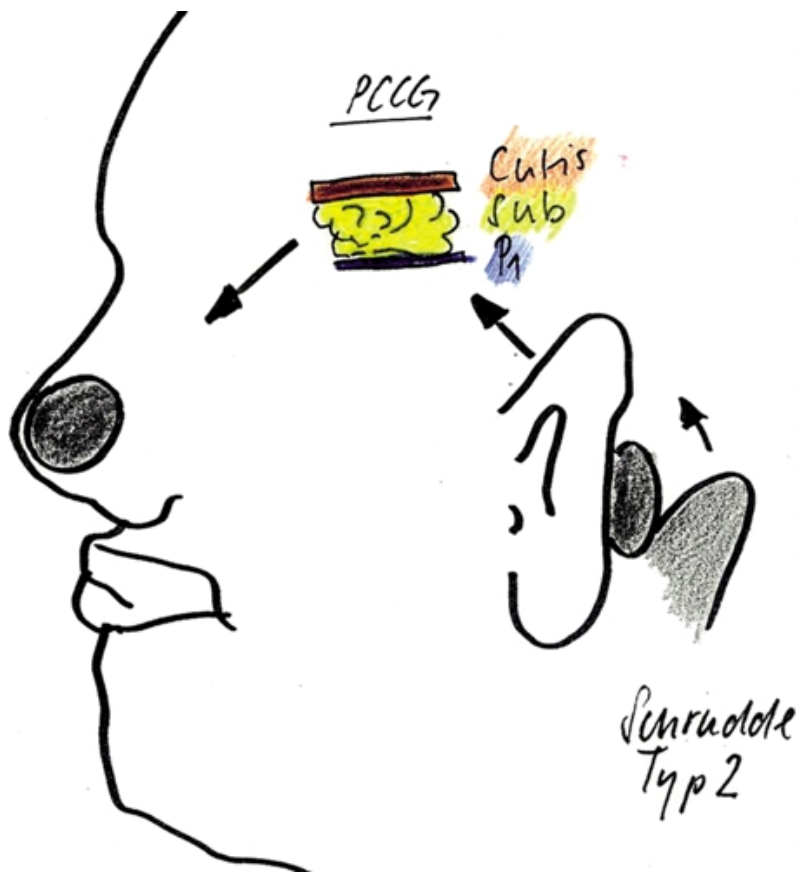

Fig. 1. Schematic drawing of the principle underlying the operative procedure.

The graft consists of epidermis, dermis, scant subcutaneous tissue, and the outer (fibrous) perichondrial layer. The presence of this fibrous layer results in excellent wound healing, provides additional stability, and prevents contraction and depressed contour formation, all issues of concern in fullthickness skin grafting [1]. At the donor site, the remaining inner (cambium) layer is advantageous for wound healing $[3,4,10]$.

This report aims is to present our results obtained with the PCCG harvested from a less conspicuous, easy-to-reconstruct posterior auricular donor site for coverage of nasal defects after resection of basal cell carcinoma resulting in unstable nostrils.

\section{Materials and Methods}

Patients with basal cell carcinoma of the nasal ala and tip were enrolled in this study if tumor resection included parts of the fibrofatty tissue or tip cartilage, resulting in mechanically unstable nostrils. After excision and immediate frozen section analysis with confirmation of total resection, the defect surface area was assessed with a template of the skin defect, which also served for planning of the graft (Fig. 2). For graft harvest, the outer perichondrial layer was carefully identified and included in the graft. (Fig. 3). No resection of the conchal bowl was necessary, and conchal integrity was not affected for donor-site reconstruction. The retroauricular defect, still containing the inner perichondrial layer, can be closed

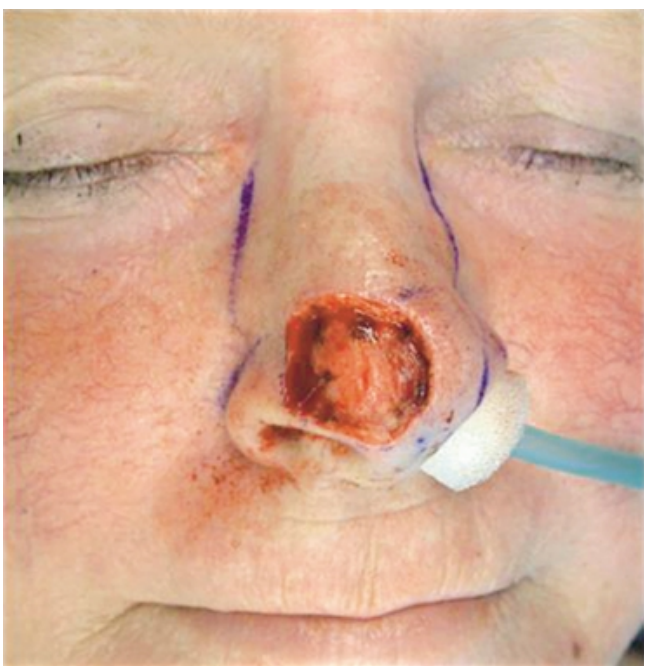

Fig. 2. Anterior view of a patient with a nasal tip defect.

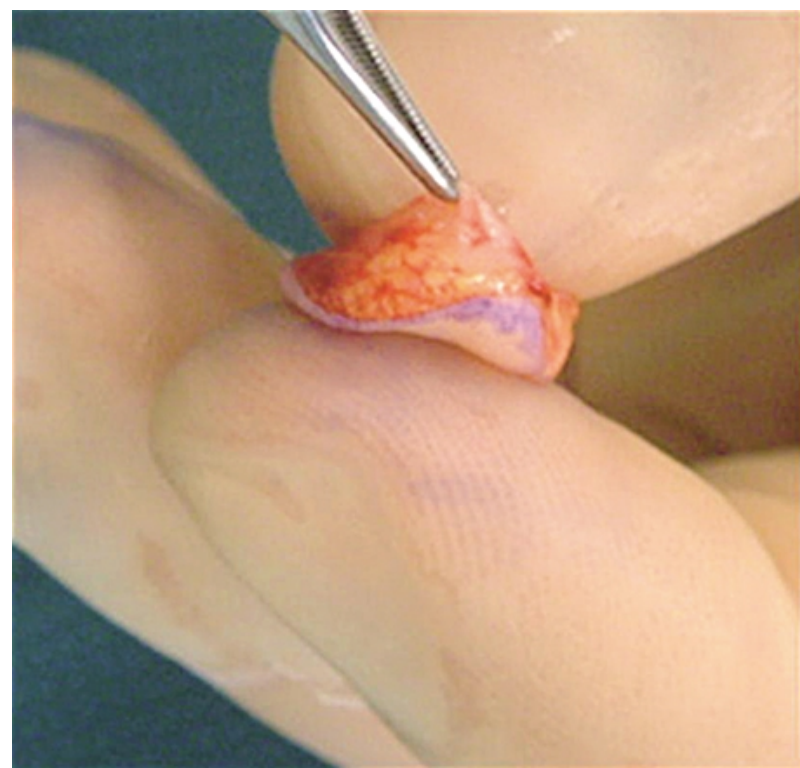

Fig. 3. Perichondrial cutaneous graft (PCCG) showing the perichondrial layer (pincher).

directly or with a local transposition flap (Fig. 4). The PCCG was sutured to the defect with nonabsorbable monofilament suture material (Fig. 5). No tie-over dressing was applied. Graft cooling with the application of refrigerated saline solution was performed for the first 4 postoperative days by the patients to slow down metabolic processes.

A modified tension spring balance was used to quantify the compression force needed on each ala, and to allow the stability of the reconstructive result to be assessed in a quick and reproducible way (Fig. 6). Maximal compression forces needed to collapse the ala on the surgically managed side were compared with those needed on the contralateral 


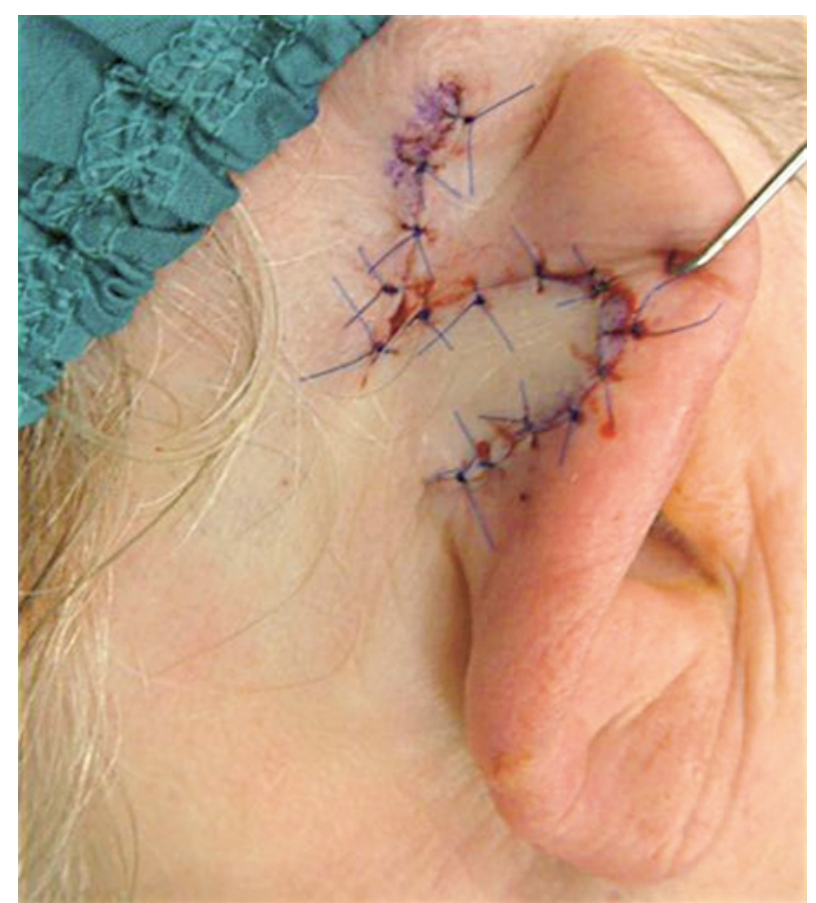

Fig. 4. Retroauricular defect covered with a transposition flap.

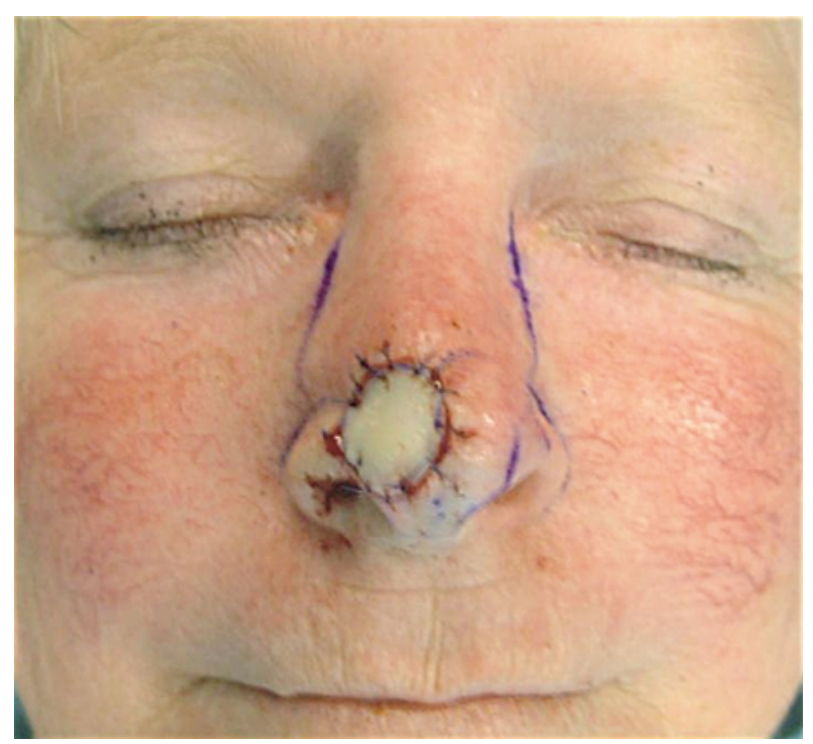

Fig. 5. Postoperative view showing the sutured perichondrial cutaneous graft (PCCG).

side. Symmetric compression forces signify mechanically stable conditions of the reconstructed zone.

\section{Results}

The noses of 14 patients ( 9 men and 5 women, average age, 73 years; range, $46-91$ years) with solid

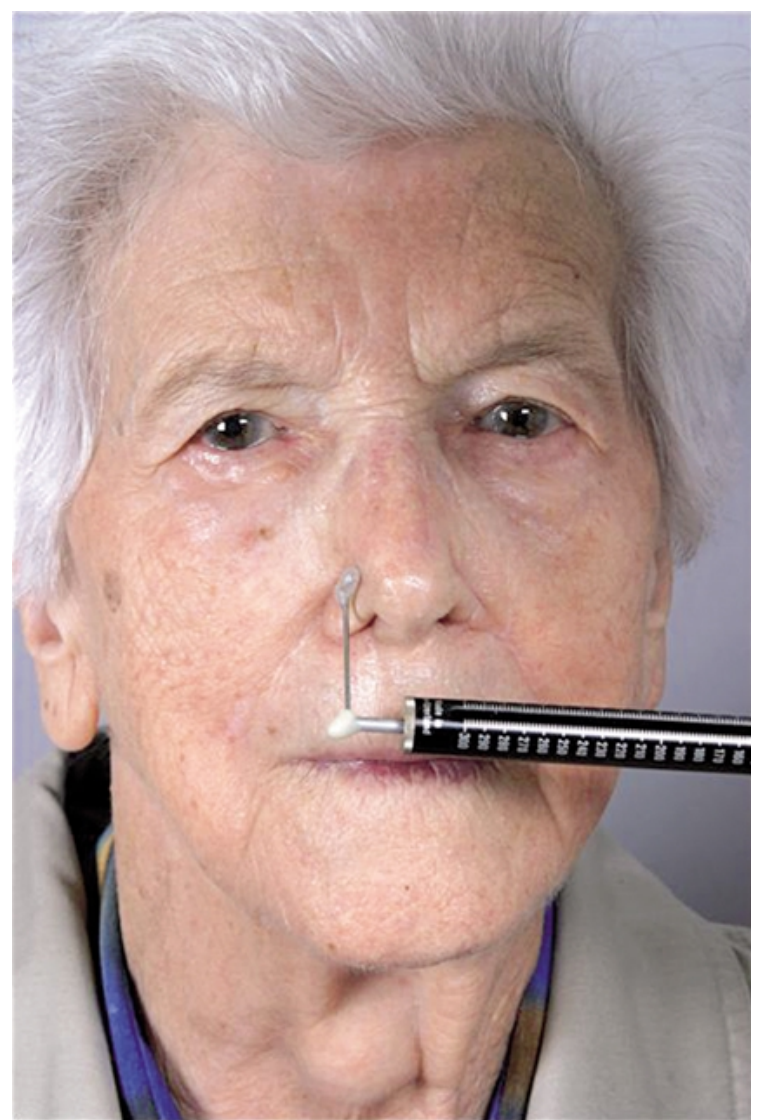

Fig. 6. Modified tension spring device to measure stability of the nasal ala and tip.

or szirrhous basal cell carcinoma were reconstructed with a posterior auricular PCCG. The location of the defect was the ala of the nose in nine cases and the tip of the nose in five cases (Fig. 7). After 2 weeks, 11 $(79 \%)$ of the 14 cases showed primary complete healing. The remaining three patients had partial necrosis, which healed completely by secondary intention. Because of fulminate infection, one of the patients experienced complete superficial skin slough that healed without further intervention (Figs. 8-10). In all three patients, signs of infection were present before the development of partial necrosis.

The average defect size was $2 \mathrm{~cm}^{2}$ (range, $1.0-2.5$ $\mathrm{cm}^{2}$ ) on the ala and $2.5 \mathrm{~cm}^{2}$ (range, $1.8-2.7 \mathrm{~cm}^{2}$ ) on the tip. The average follow-up period was 12.2 months (range, 6-20 months) for ala grafts and 13.6 months (range, 7-18 months) for tip grafts (Table 1). At 6 months postoperatively, all 14 PCCGs were without signs of contraction or depressed contour (Figs. 11-15). In one case, a hyperpigmented area resulted in a slightly imperfect color match.

Stability was almost symmetric, with a mean difference of only $0.2 \mathrm{~N}$ (Fig. 16). Donor sites healed uneventfully without deformity or destabilization of the ear, and without any reports of pain or other sensory problems. 

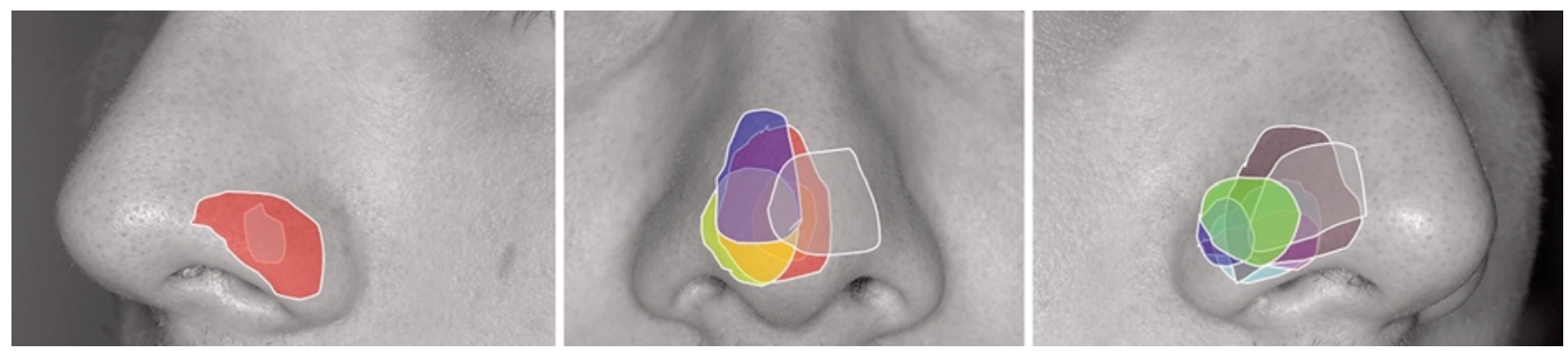

Fig. 7. Overview of the different defect locations.

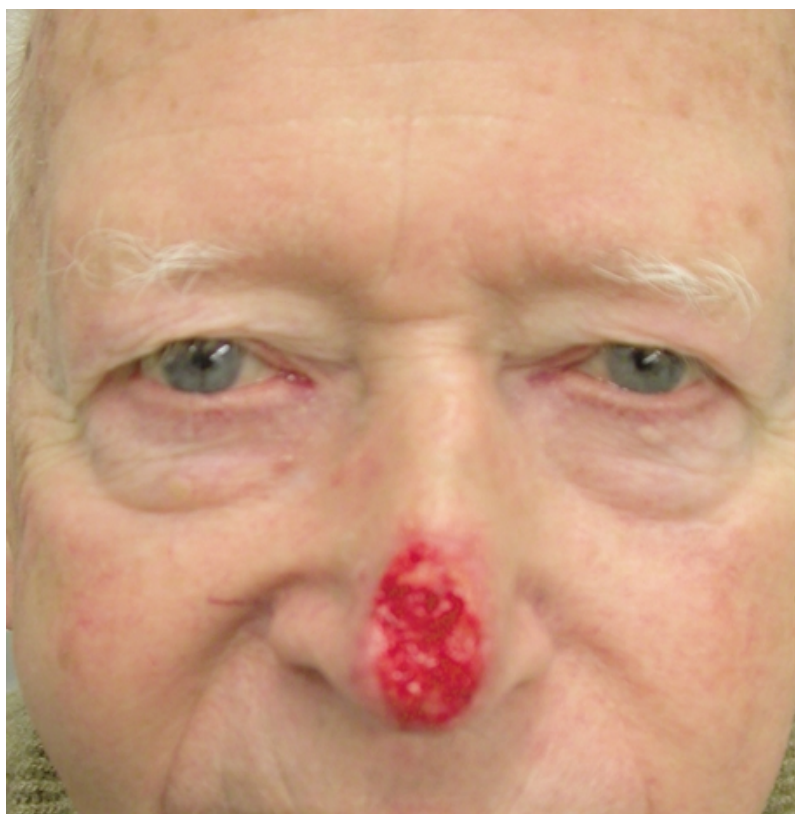

Fig. 8. Patient (worst case) who experienced infection leading to complete superficial skin slough.

\section{Discussion}

Because of the PCCG's unique composition consisting of epidermis, dermis, scant subcutaneous tissue, and a perichondrial plexus in the underlying perichondrium, as well as its naturally curved contour, it has proved to be of great value in the reconstruction of different sites $[1,2,7]$. The use of a posterior auricular donor site for the PCCG instead of the anterior conchal bowl allowed for simplified donor-site reconstruction. No disturbances in wound healing occurred due to the ease of reconstruction and the presence of an intact, vascularized inner perichondrial layer covering the conchal cartilage.

The anatomic difference between the anterior donor site and the posterior aspect of the ear, with its loose connections between the skin and the perichondrium and relatively thicker subcutaneous tissue, did not have any negative impact on graft take. No graft contraction occurred, and an excellent tissue

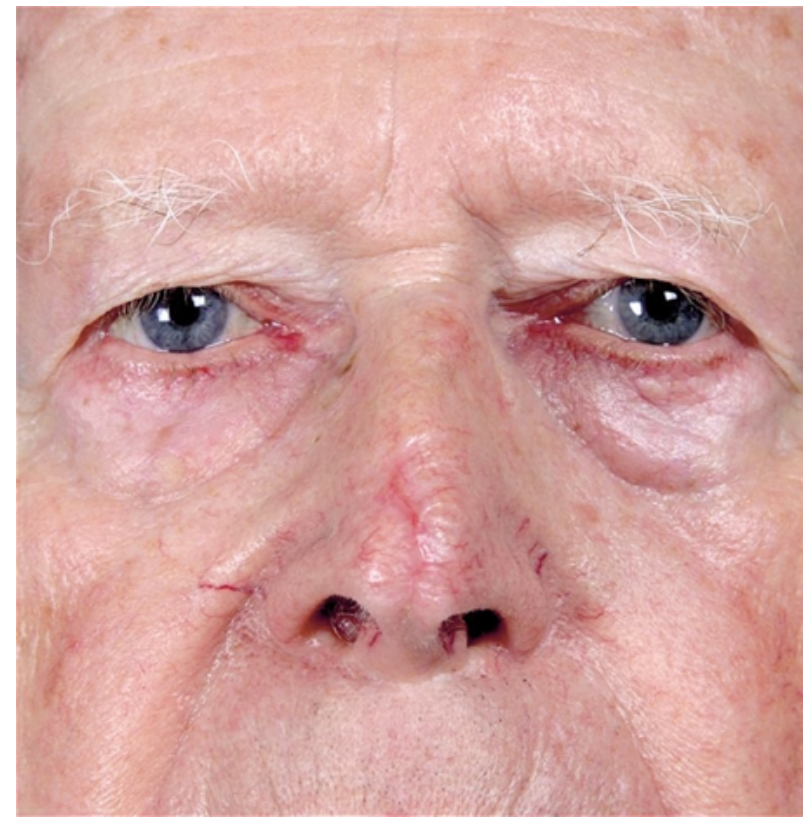

Fig. 9. Anterior view 1 year after surgery showing healing by secondary intention, with an acceptable result attributable to the surviving perichondral sheet.

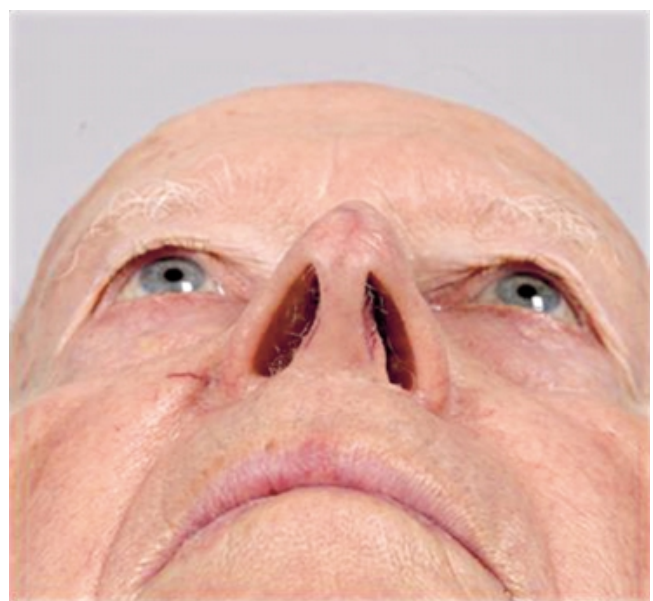

Fig. 10. Caudal view showing the reconstructed nasal arch.

match was obtained with the posterior auricular PCCG graft. All three patients with partial graft 
Table 1. Symmetric stability

\begin{tabular}{lll}
\hline & Tip & Ala \\
\hline $\begin{array}{l}\text { No. of patients } \\
\text { Gender }\end{array}$ & 9 & 5 \\
$\quad$ Male & 5 & 4 \\
$\quad$ Female & 4 & 1 \\
$\quad \begin{array}{l}\text { Age (years) } \\
\quad \text { (range) }\end{array}$ & $76.1(54-91)$ & $67.2(46-81)$ \\
$\quad \begin{array}{l}\text { Size of lesion }\left(\mathrm{cm}^{2}\right) \\
\quad \text { (range) }\end{array}$ & $2.0(1-2.5)$ & $2.5(1.8-2.7)$ \\
$\quad \begin{array}{l}\text { Wound healing } \\
\quad \text { Immediate }\end{array}$ & 8 & 3 \\
$\quad$ Late & 1 & 2 \\
$\quad \begin{array}{l}\text { Follow-up (months) } \\
\quad \text { (range) }\end{array}$ & $12.2(6-20)$ & $13.6(7-18)$ \\
\hline
\end{tabular}

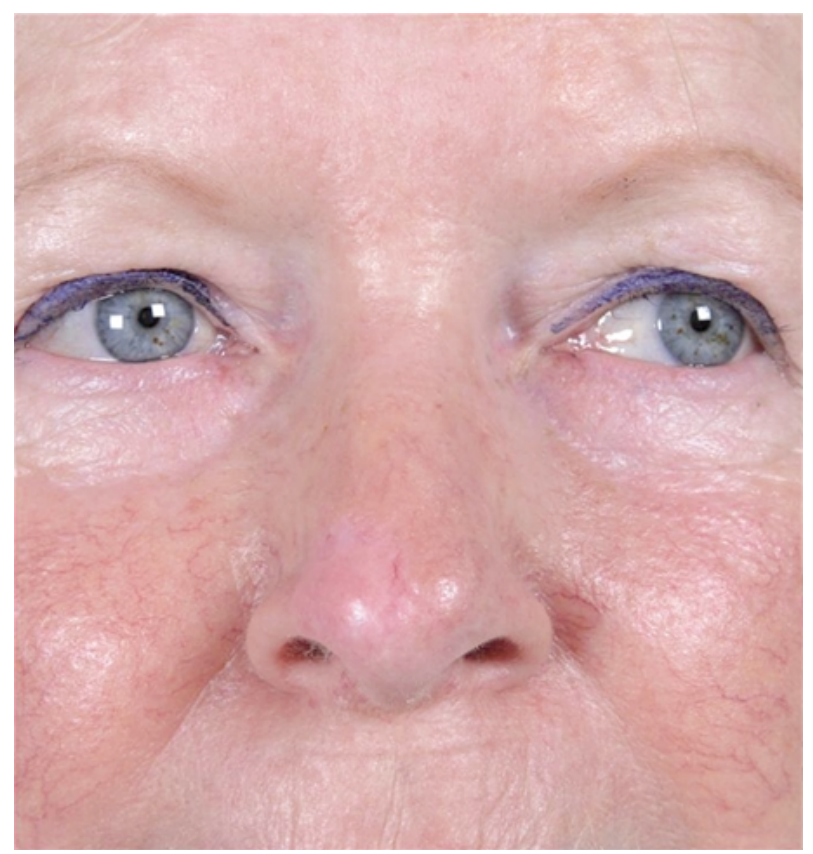

Fig. 11. Case from Fig. 1. Anterior view 1 year after surgery showing a good result.

necrosis showed early signs of infection, which is detrimental for primary healing. No revisional surgery was needed in these cases, and all healed uneventfully by secondary intention. In our opinion, this may be attributable to the persistence of an intact perichondrial layer not affected by the necrosis. Also, no association between cartilage resection for tumor clearance affecting the vascularization of the wound bed and partial necrosis was observed.

Collapse of the nostril during inspiration is a concern in reconstruction after tumor resection of the tip and ala when parts of the cartilage or the fibrofatty tissue complex are included. The use of the PCCG resulted in almost symmetric stability and no collapse during forced inspiration. It has been shown

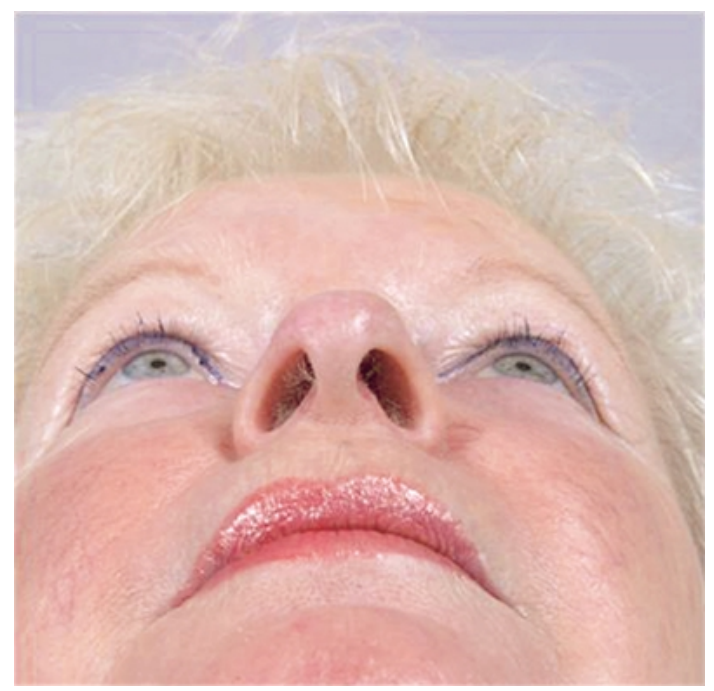

Fig. 12. Caudal view showing a good shape of the stable nasal entrance.

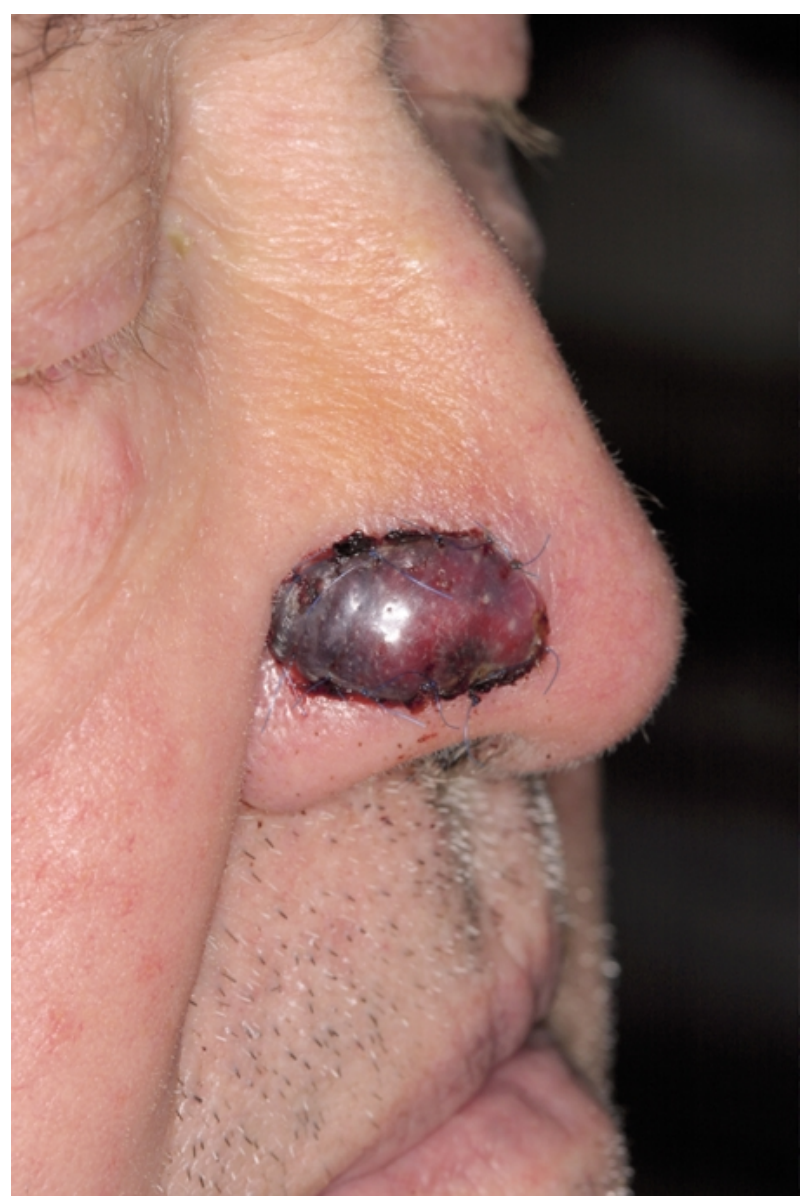

Fig. 13. Usual situation 1 week after surgery with a slightly organized graft.

that the outer layer, included in the graft, rapidly produces fibrous growth and provides stable con- 


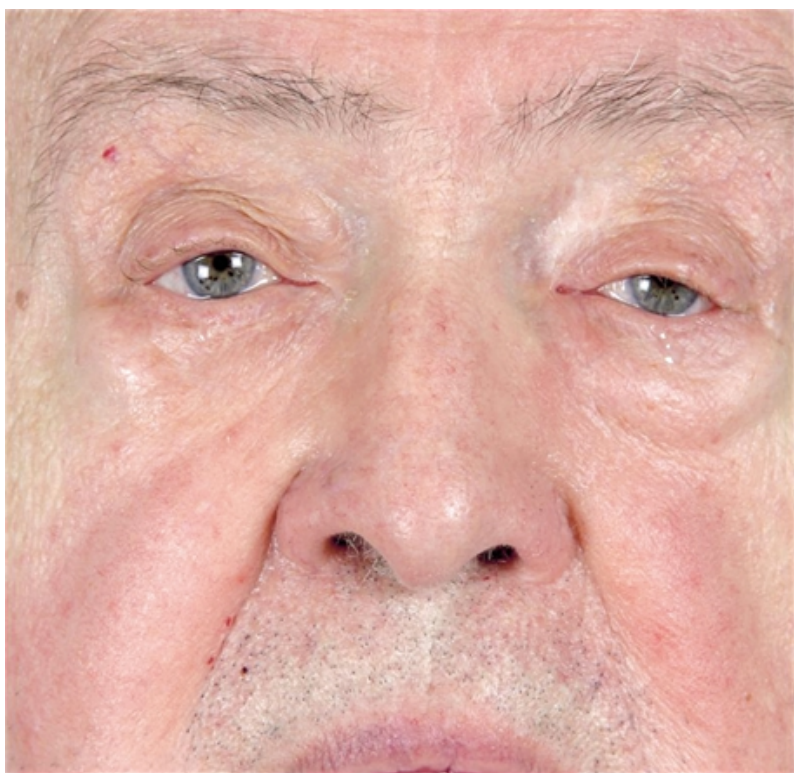

Fig. 14. Anterior view 20 months after surgery showing a good result.

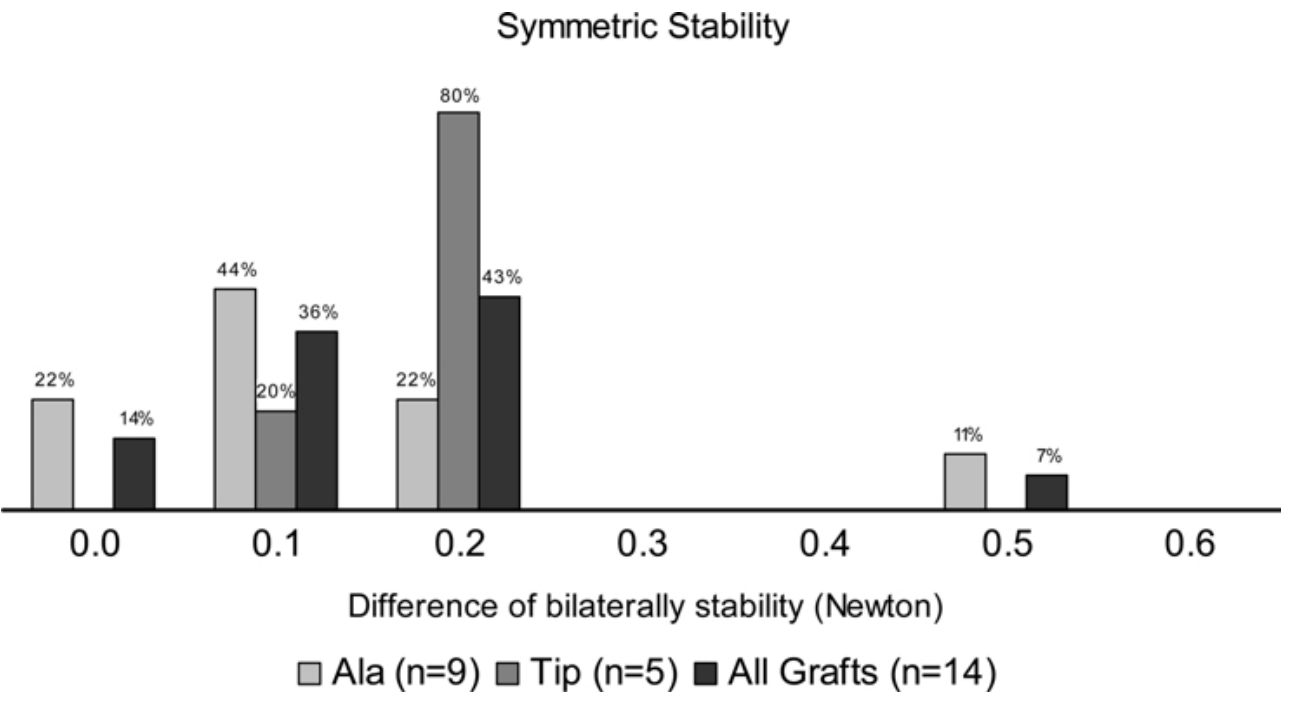

Fig. 16. Stability analysis of the ala using a tension spring balance. nections to the wound bed important for the mechanical function of the structure [3]. This might be responsible for the stability obtained after reconstruction with the PCCG.

As an additional precaution, refrigerated saline solution was used to cool the dressing for the first 4 postoperative days in our series because no previous reports on survival of the thicker posterior auricular PCCG were available. The principle of cooling has been applied to decrease metabolic demands of the graft and thereby increase the success rate [2]. However, although all patients were instructed to cool the dressing regularly, control of compliance is difficult, and no comment can be made on the effectiveness of this additional procedure.

\section{Conclusion}

An elegant principle in the practice of plastic surgery is to keep the reconstruction as simple as possible. In this study, we simplified the established PCCG by using the posterior auricular donor site instead of the anterior conchal bowl. Donor-site morbidity can be decreased with this modified method, and the natural shape of the ear is completely preserved. A functional and aesthetic reconstruction of the nose can be achieved and, at the same time, no additional scars are created when a PCCG is used. Graft morbidity is very low, and the results are fully satisfying, supporting further use of the PCCG from the posterior auricular donor site. 
Acknowledgments. We acknowledge Stefan De Maddalena, University Basel, for technical support in the photographic workup, Stacy $\mathrm{Wu}$, MD, University Basel, for manuscript revision, and Natalie du Croo de Jongh, M.D., Bern, for scientific assistance.

\section{References}

1. Brent B, Ott R: Perichondrocutaneous graft. Plast Reconstr Surg 62:1-14, 1978

2. Conley JJ, Vonfraenkel PH: The principle of cooling as applied to the composite graft in the nose. Plast Reconstr Surg 17/6:444-451, 1956

3. Duynstee MLG, Verwoerd-Verhoef HL, et al.: The dual role of perichondrium in cartilage wound healing. Plast Reconstr Surg 110/4:1073-1079, 2002

4. Eisemann ML: The growth potential of autograft cartilage: An experimental study. Arch Otolaryngol 109:469-472, 1983
5. Ohsumi N, Iida N: Ear reconstruction with chondrocutaneous postauricular island flap. Plast Reconstr Surg 96:718-722, 1995

6. Park C, Shin KS, et al:: A new arterial flap from the postauricular surface: Its anatomic basis and clinical application. Plast Reconstr Surg 82:498-502, 1988

7. Portuese W, Stucker FJ, et al.: Perichonrial cutaneous graft. Arch Otolaryngol Head Neck Surg 115:705-709, 1989

8. Renard A: Postauricular flap based on a dermal pedicle for ear reconstruction. Plast Reconstr Surg 68: $159-165,1981$

9. Stucker FJ, Shaw GY: The perichondrial cutaneous graft. Arch Otolaryngol Head Neck Surg 118:287-292, 1992

10. Upton J, Sohn SA, et al.: Neocartilage derived form transplanted perichondrium: What is it? Plast Reconstr Surg 68:166-172, 1981

11. Van Osch G, Van der Veen SW, et al.: Chondrogenic potential of in vitro multiplied rabbit perichondrium cells cultured in alginate beads in defined medium. Tissue Eng 6/4:321-330, 2000 